\title{
Study on the Difference of Stability Calculation Between Numerical Simulation Analysis and Limit Equilibrium Methods--Take Huangmuya Landslide as an Example
}

\author{
Zhao Changjun ${ }^{1}$, Wu Liudong ${ }^{2}$, Jiang Nan ${ }^{2}$, Xu Minghui ${ }^{1}$ \\ ${ }^{1}$ Changjiang Institute of Survey, Planning, Design and Research, Wuhan, China \\ ${ }^{2}$ China Southwest Geotechnical Investigation \& Design Institute Co., Ltd, Chengdu, China
}

Email address:

genghiskhanchina-m@163.com (Zhao Changjun),maxwuld@126.com (Wu Liudong)

To cite this article:

Zhao Changjun, Wu Liudong, Jiang Nan, Xu Minghui. Study on the Difference of Stability Calculation Between Numerical Simulation Analysis and Limit Equilibrium Methods--Take Huangmuya Landslide as an Example. American Journal of Mechanics and Applications. Vol. 9, No. 2, 2021, pp. 12-17. doi: 10.11648/j.ajma.20210902.11

Received: April 23, 2021; Accepted: June 8, 2021; Published: June 21, 2021

\begin{abstract}
Numerical simulation analysis and limit equilibrium methods are usually used in landslide stability analysis. In order to study the differences of calculation theory and results, this paper takes Huangmuya landslide as a case study. The field geological survey and exploration are used to determine the form and property of the landslide. The deformation characteristics and stability state are comprehensive analyzed based on the information of macroscopic inspection and professional monitoring data. It is considered that the potential slip zone of the landslide has not obviously deteriorated, and the induced formation mechanism of the landslide mainly comes from the process and deformation of the upper slip mass. Through the analysis, FLAC3D is applied to simulate the stability of Huangmuya landslideis. The numerical simulation results show that the displacement of the slope will further increase, mainly concentrated in the middle and leading edge of the slip mass. Besides, stability coefficients are calculated by five limit equilibrium methods. The relationship of stability coefficients is as follows: transfer coefficient method > Low method > US Army Corps of Engineers method $>$ M-P method $>$ Janbu method. Based on the numerical simulation results, it is recommended to give priority to the US Army Corps of Engineers method, Low method or M-P method as the stability calculation method because the deviation amount is all within $\pm 2 \%$.
\end{abstract}

Keywords: Huangmuya Landslide, Stability Calculation, Numerical Simulation Analysis, Limit Equilibrium Method

\section{Introduction}

Limit equilibrium methods are widely used for landslide stability analysis based on their convenience and high efficiency, including transfer coefficient method, US Army Corps of Engineers method, Low method, Janbu method and Morgenstern-Price method (M-P method). However, landslide stability is affected by multiple uncertain and complex factors. Analysis results are different and non-ideal due to simple assumptions of different methods [1]. Many researchers have researched the relationships between analysis results [2, 3] and optimized limit equilibrium methods [4, 5].

At present, numerical simulation analysis have been one of main methods of landslide stability analysis while high-speed developing of computer. FLAC3D is used to simulate the behavior of structures built of soil, rock or other materials, which may undergo plastic flow when their yield limit is reached $[6,7]$. The basic theories of this method are introduced in many papers $[8,9]$.

In this paper, the stability of Huangmuya landslide is analyzed by limit equilibrium methods and numerical simulation adopted FLAC3D software, combined with the results of professional monitoring. The characteristics of stress and displacement distribution are studied to reveal the landslide mechanism. And the relationships between stability coefficient calculation results are pointed out to verify the accuracy of limit equilibrium methods. 


\section{Geological Characteristics of Landslide Area}

\subsection{General Situation of Landslide}

Huangmuya landslide is located in the high and steep slope area on the right bank of Yesanhe deep V-shaped canyon, a tributary of Qingjiang River, which is about $40 \mathrm{~km}$ away from Shuibuya Dam. The plane shape of the landslide is "triangular", the elevation of the leading edge is $280 \mathrm{~m}$, the elevation of the trailing edge is $730 \sim 816 \mathrm{~m}$, the thickness of the slip mass is about $60 \sim 120 \mathrm{~m}$, the area is about $276,000 \mathrm{~m}^{2}$ and the volume is 17.8 million $\mathrm{m}^{3}$. Among them, the area of the underwater slip mass below $400 \mathrm{~m}$ elevation is $88,200 \mathrm{~m}^{2}$ and the volume is 2.64 million $\mathrm{m}^{3}$, accounting for $32 \%$ and $14.8 \%$ of the total area and volume of the slip mass respectively (see figure 1).
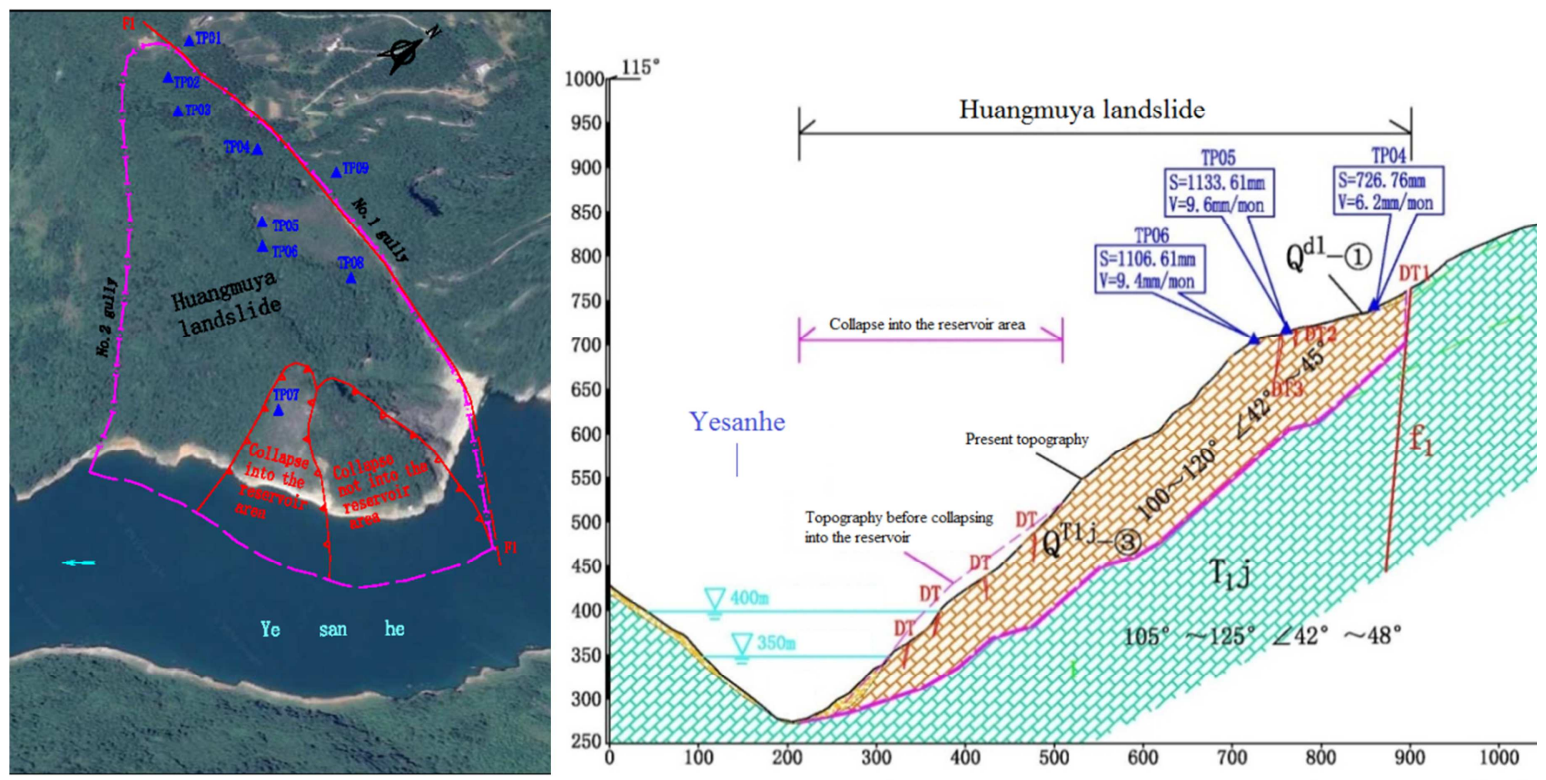

Figure 1. Panoramic map and typical geological longitudinal profile of Huangmuya landslide.

\subsection{Basic Geological Conditions of Landslide Area}

The Shuibuya reservoir impoundment began in October 19 2006, which the storage capacity is 4.312 billion $\mathrm{m}^{3}$. The normal water level of reservoir is $400 \mathrm{~m}$, the dead water level is $350 \mathrm{~m}$. The strata in the landslide area are mainly composed of Quaternary loose accumulation layer $\left(\mathrm{Q}_{4}\right)$ and Triassic $(\mathrm{T})$ strata. The f1 fault is mainly developed in the area, whose occurrence is $160-170^{\circ} \angle 75-85^{\circ}$ and length is more than 1 $\mathrm{km}$. Karst phenomenon in the landslide area is common because of the soluble rock. No. 1 gully and No. 2 gully are mainly developed, both of which are seasonal dry ditches. Surface water discharge condition in the landslide area is good. The groundwater is buried deeply, and the hydraulic slope is small [10].

\subsection{Main Geological Characteristics of Landslide}

The material composition of the slip mass is generally divided into three layers from top to bottom: the upper layer is limestone crushed stone with silty clay layer $\left(Q^{\mathrm{dl}}-(1)\right)$, which is $1 \sim 30 \mathrm{~m}$ thick, the structure is loose to slightly dense, and it is moderately permeable. The middle layer is a layered limestone cataclastic rock which has slid $\left(\mathrm{Q}^{\mathrm{T} 1 \mathrm{j}}{ }_{-}(2)\right), 20 \sim 50 \mathrm{~m}$ thick, with sequence structure, and the local rock mass is relatively complete and moderately permeable. The lower layer is layered limestone fractured rock $\left(\mathrm{Q}^{\mathrm{Tlj}}-(3)\right)$, with a thickness of $60 \sim 120 \mathrm{~m}$, relatively complete and continuous distribution, which is micro to extremely micro permeable. The main geological characteristics of the landslide are shown in figure 1.

The potential sliding bed surface is developed in a way of stair-step shape and consequent bedding, the middle and upper part is bedding, the overall slightly cut layer, the inclination angle is $37 \sim 42^{\circ}$, the leading edge is slightly slow, and the potential slip zone is $0.3 \mathrm{~m}$ thick. The underlying stable bedrock is the limestone of the Lower Triassic Jialingjiang River formation $\left(T_{1} j\right)$, which rock mass is fresh and intact.

\section{Deformation Characteristics and Stable Status Quo of Landslide}

\subsection{Macroscopic Deformation Characteristics}

A slip mass of $300,000 \mathrm{~m}^{3}$ slid below the $550 \mathrm{~m}$ elevation of the leading edge adjacent to the reservoir of the landslide area on June 22, 2007. The cumulative volume of the reservoir-entering slip mass is about $900,000 \mathrm{~m}^{3}$, and the deformation range along the edge of the reservoir is about $300 \mathrm{~m}$.

The shallow slip mass below the elevation of $475 \mathrm{~m}$ in the north-east of No. 1 gully adjacent to the reservoir has crept as a whole. Intense tensile and bulging deformation has been formed on the earth surface. Horizontal displacement 
distance is more than $200 \mathrm{~cm}$ and the maximum crack width reaches $60 \mathrm{~cm}$. Serious deformation area is about $50,600 \mathrm{~m}^{2}$ and the volume is about 1.6 million $\mathrm{m}^{3}$.

Since June 29th, 2007, many ground fissures such as DT1, DT2, DT3 have been found in trailing edge of the landslide, with a fracture strike of $40 \sim 80^{\circ}$, an extension length of $20 \sim 360 \mathrm{~m}$, a tension fracture width of $10 \sim 300 \mathrm{~cm}$ and a height of $10 \sim 60 \mathrm{~cm}$. These fissures are in continuous deformation. Among them, DT1 fracture is controlled to form by f1 fault, which has the largest scale and the most severe deformation.

\subsection{Professional Monitoring and Analysis}

The professional monitoring network, shown in figure 1 , is arranged based on "Monitoring code of rockfall, landside and debris flow (DZ/T 0221-2006)" [11]. There are 9 monitoring points in and around the landslide, and the reference points are located on the opposite bank. According to the monitoring results of 11 consecutive years since January 2009, the analysis and summary of professional monitoring results are shown in figures 2 and table 1 respectively.

\subsection{Stable Status Quo}

It is considered that the potential slip zone of the landslide has not obviously deteriorated, and the induced formation mechanism of the landslide mainly comes from the process and deformation of the upper slip mass. The long-term evolution trend of the landslide depends on the sliding driving force of the upper slip mass and the resistance of the leading slip mass. The landslide as a whole is in under stable state [12].

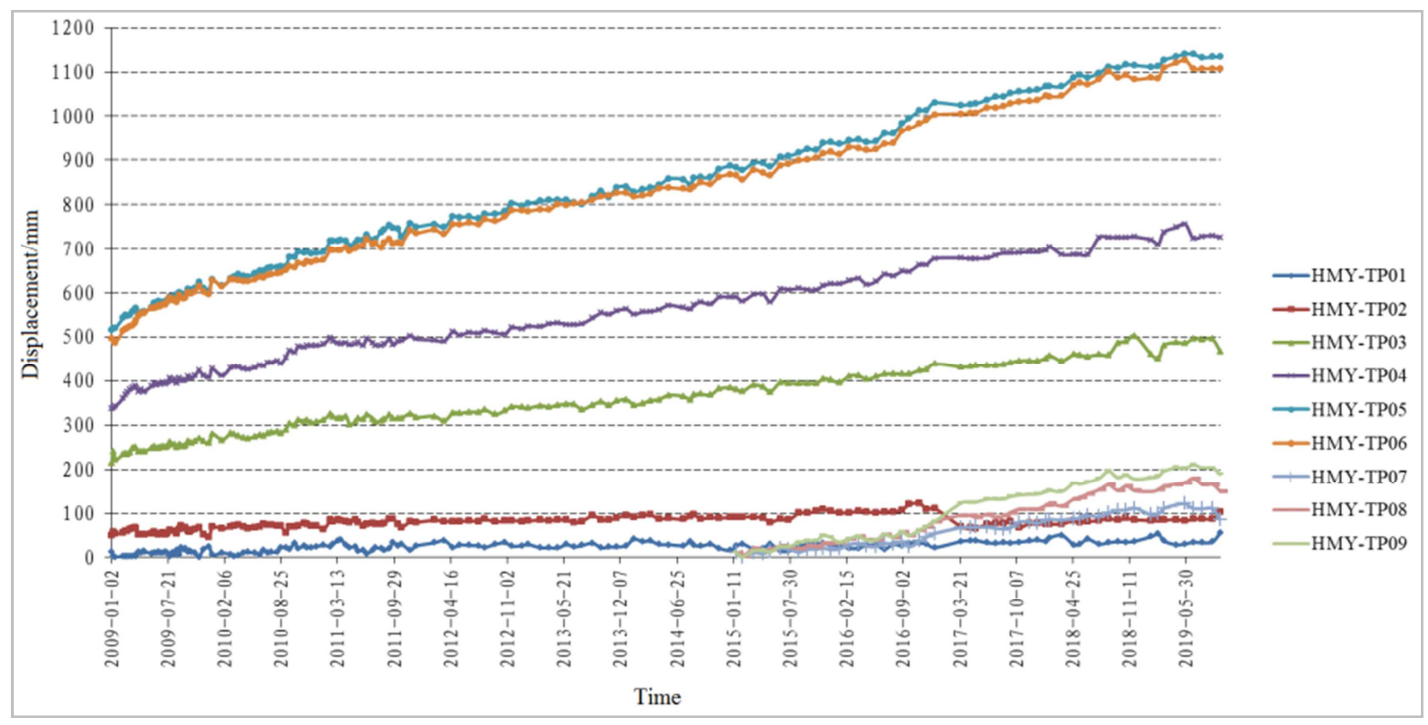

Figure 2. Trend chart of cumulative horizontal displacement of monitoring points.

\section{Stability Calculation and Comparative Analysis}

\subsection{Numerical Simulation Analysis}

According to the two-dimensional geological model of the landslide, a three-dimensional entity per unit thickness is established, and the displacement constraint is applied in the $\mathrm{Z}$ direction to realize the plane strain analysis. The grid number of the whole model is 6560 and the number of nodes is 8326 [13].

The stress-strain distribution and stable state of the landslide status quo are numerically simulated by FLAC3D. The physical and mechanical parameters of slip mass and sliding bed are shown in Table 2. The contour of displacement, shear strain increment cloud map and plastic zone distribution map in the evolution of landslide are shown in figure 3, and the calculation results of stability coefficient are shown in Table 3.

Table 1. Analysis table of professional monitoring results of landslide (2009.01.02-2019.09.27).

\begin{tabular}{lll}
\hline \multirow{2}{*}{ Monitoring point } & \multicolumn{2}{c}{ Displacement $(\mathbf{m m}) /$ monthly deformation rate $(\mathbf{m m} / \mathbf{m o n t h})$} \\
\cline { 2 - 3 } & Horizontal & vertical \\
\hline Outer edge TP01 & $84.82 / 0.47$ & $59.00 / 0.46$ \\
Trailing edge TP02 & $103.71 / 0.88$ & $670.70 / 5.20$ \\
Front part TP07 & $110.60 / 1.46$ & $33.70 / 0.59$ \\
Northern part TP08 & $166.66 / 2.59$ & $84.50 / 1.48$ \\
Outer edge TP09 & $189.42 / 3.27$ & $202.70 / 3.56$ \\
Rear part TP03 & $467.26 / 3.96$ & $1185.40 / 9.26$ \\
Trailing edge TP04 & $726.76 / 6.16$ & $1586.40 / 12.30$ \\
Rear part TP05 & $1133.61 / 9.61$ & $843.20 / 6.53$ \\
Rear part TP06 & $1106.61 / 9.38$ & $793.10 / 6.150$ \\
\hline
\end{tabular}


Table 2. Physical and mechanical parameters of slip mass and sliding bed.

\begin{tabular}{|c|c|c|c|c|c|c|c|c|c|}
\hline \multirow{2}{*}{ Name of substance } & \multicolumn{2}{|c|}{ Heavy degree $\gamma\left(\mathrm{kN} / \mathrm{m}^{3}\right)$} & \multicolumn{2}{|c|}{ Cohesion $c$ (kPa) } & \multicolumn{2}{|c|}{ Internal friction angle $\varphi\left({ }^{\circ}\right)$} & \multirow{2}{*}{$\begin{array}{l}\text { Young's modulus } \\
E(\mathrm{GPa})\end{array}$} & \multicolumn{2}{|c|}{ Poisson's ratio $\mu$} \\
\hline & $\mathbf{a}$ & b & $\mathbf{a}$ & b & $\mathbf{a}$ & b & & $\mathbf{a}$ & b \\
\hline Layered fractured rock & 25.5 & 26.5 & 80 & 75 & 34 & 32 & 4.9 & 0.38 & 0.38 \\
\hline Layered cataclastic rock & 23.0 & 24.5 & 60 & 55 & 30 & 28 & 2.5 & 0.39 & 0.40 \\
\hline Limestone & 27.0 & & 800 & & 60 & & 28.5 & 0.29 & \\
\hline
\end{tabular}

Note: a means nature state, $b$ means saturation state.
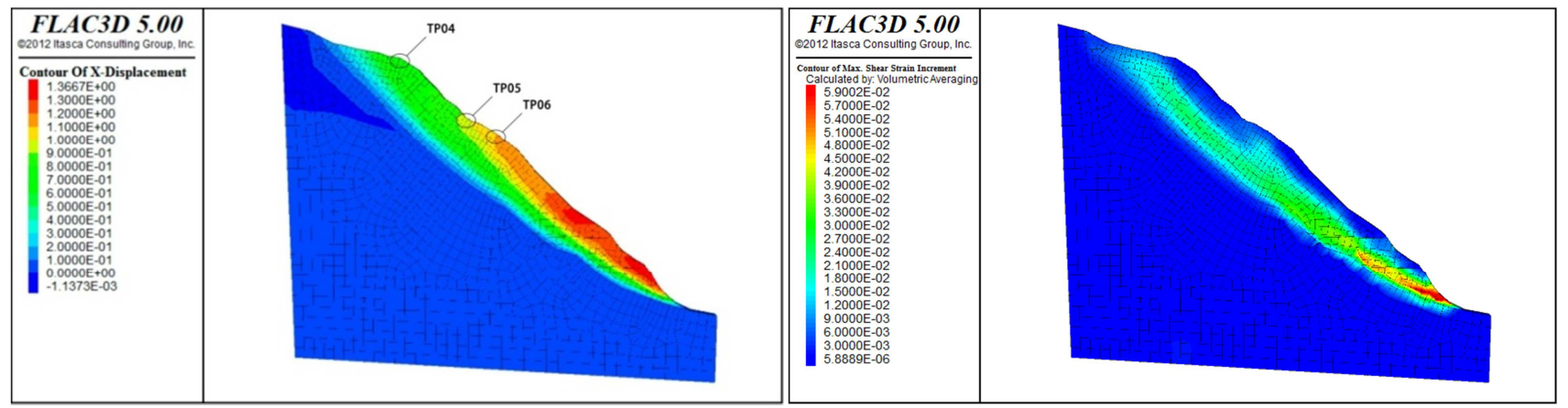

Figure 3. Displacement isoline map and shear strain increment cloud map in the evolution of landslide.

Table 3. Calculation results of stability coefficient of numerical simulation.

\begin{tabular}{llllll}
\hline Working condition & Condition 1 & Condition 2 & Condition 3 & Condition 4 & Condition 5 \\
\hline Stability coefficient & 1.064 & 1.047 & 1.061 & 1.014 & 1.011 \\
\hline
\end{tabular}

Note: Condition 1: Dead weight + reservoir characteristic water level 350m, Condition 2: Dead weight + reservoir characteristic water level 400m, Condition 3: Dead weight + reservoir characteristic water level $350 \mathrm{~m}+$ the rainstorm once in two decades in flood season, Condition 4: Dead weight + reservoir characteristic water level $400 \mathrm{~m}+$ the rainstorm once in two decades in non-flood season, Condition 5: Dead weight + reservoir water level dropped from $400 \mathrm{~m}$ to $380 \mathrm{~m}+$ the rainstorm once in two decades in non-flood season.

As can be seen from figure 3, the cumulative horizontal displacements of TP04, TP05 and TP06 at the monitoring points at the trailing edge of landslide calculated by numerical simulation are $712.7 \mathrm{~mm}, 1054.2 \mathrm{~mm}$ and $1107.3 \mathrm{~mm}$. In addition, the maximum displacement area of the landslide is distributed in the middle and leading edge of the landslide, but the monitoring points cannot be set up on the site because of steep topography. The calculated results of numerical simulation of displacement are basically consistent with the actual monitored deformation. Under the current shape of the slope, the shear stress concentration zone is distributed in the contact zone and its periphery of the sliding zone of slip mass, in which the shear strain at the shear exit is more concentrated.

The numerical simulation results show that the landslide is currently in an unstable state, and under the current evolution conditions, the displacement of the slope will further increase, mainly concentrated in the middle and leading edge of the slip mass, while the tensile cracks at the trailing edge will expand gradually. As a whole, there is a risk of slip shear failure.

\subsection{Comparative Analysis of Limit Equilibrium Method}

Five limit equilibrium methods including transfer coefficient method, US Army Corps of Engineers method, Low method, Janbu method and M-P method are used respectively to calculate stability of the landside $[14,15]$. The physical and mechanical parameters of the slip mass are shown in Table 2, and the calculation results of stability coefficient are shown in Table 4.

Table 4. Calculation results of stability coefficient of landslide.

\begin{tabular}{lllll}
\hline \multirow{2}{*}{ Calculating method } & Stability coefficient & & & \\
\cline { 2 - 5 } & Condition 1 & Condition 2 & Condition 3 & Condition 4 \\
\hline Transfer coefficient method & 1.0796 & 1.0693 & 1.0775 & 1.0652 \\
US Army Corps of Engineers method & 1.0501 & 1.0285 & 1.0476 & 1.0614 \\
Low method & 1.0534 & 1.0405 & 1.0508 & 1.0133 \\
Janbu method & 0.9983 & 0.9786 & 0.9960 & 1.0318 \\
M-P method & 1.0457 & 1.0181 & 1.0436 & 0.9671 \\
\hline
\end{tabular}

It can be seen from Table 4 that the calculation result of the stability coefficient is a monotone increasing function of the dip angle of the force between the slices, and the relationship is as follows: transfer coefficient method $>$ Low method > US Army Corps of Engineers method > M-P method $>$ Janbu method.

In order to judge the degree of deviation between the stability coefficient calculation results of different limit 
equilibrium methods and the numerical simulation analysis, the deviation amount is calculated according to formula (1), and the calculated results are shown in figure 4.

$$
\delta=(B-A) / A
$$

In the formula: $\delta$ is the deviation amount $(\%) ; A$ is the stability coefficient calculation results of numerical simulation analysis; $B$ is the stability coefficient calculation results of transfer coefficient method, US Army Corps of Engineers method, Low method, Janbu method and M-P method.

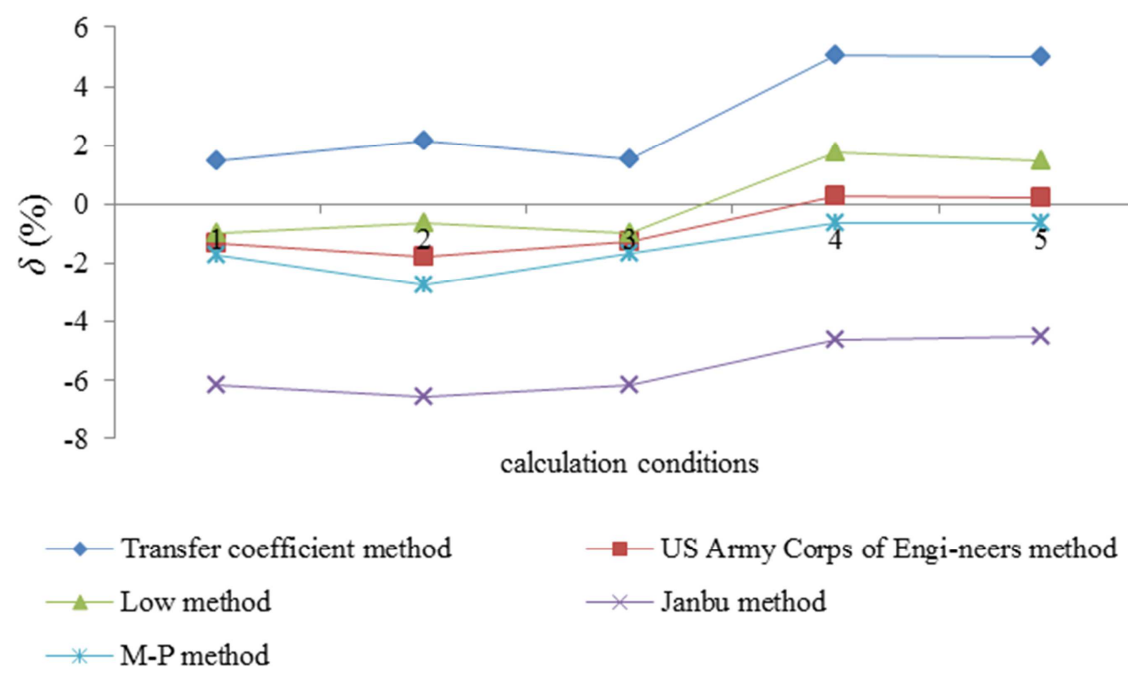

Figure 4. The deviation amount of the calculation result of the stability coefficient of the limit equilibrium method.

As can be seen from figure 4 , the stability coefficient calculation results of Janbu method is the lower bound solution among limit equilibrium methods. And the deviation amount from the numerical simulation result is-4.5 -6.5\%. The deviation amount between the stability coefficient calculation result of the transfer coefficient method and the numerical simulation analysis result is $1.5 \sim 5.0 \%$. The calculation results of the stability coefficient of the US Army Corps of Engineers method, Low method and M-P method are close to the results of the numerical simulation analysis, and the deviation amount is all within $\pm 2 \%$. So the landslide is judged in an unstable state, which is more consistent with the actual situation of the landslide site. It is recommended to give priority to the US Army Corps of Engineers method, Low method or M-P method as the stability calculation method of this kind of landslide.

\subsection{Defects of Numerical Simulation Analysis and Limit Equilibrium Method}

Through comparative study of the above two kinds of calculation methods, it can be seen that the stress-strain relationship of rock and soil is taken into account in the numerical simulation analysis, which can directly reflect the displacement and plastic zone distribution of the slip mass, but the reliability of the simulation results must be based on professional monitoring. Although the calculation of the limit equilibrium method is simple and feasible, the assumption of the complex interaction force between the slices is too simple to truly reveal the magnitude and direction of the internal force of the slip mass. From that, the above two kinds of calculation methods are affected by many man-made factors, which bring the difference of calculation results.

\section{Conclusion}

(1) The stress-strain relationship of rock and soil is taken into account in the numerical simulation analysis, and the calculation results can reflect the displacement values of each part of the model, but the calculation process is complex and must be based on professional monitoring. Although the calculation of the limit equilibrium method is simple and feasible, calculation results of stability coefficient are quite different from each other.

(2) The stability coefficient calculated by different limit equilibrium methods is a monotone increasing function of the inclination angle between slices, and the relationship is as follows: transfer coefficient method $>$ Low method $>$ US Army Corps of Engineers method $>$ M-P method $>$ Janbu method.

(3) It is recommended to give priority to the US Army Corps of Engineers method, Low method or M-P method as the stability calculation method of this kind of landslide because the stability coefficient calculation results are close to the results of numerical simulation.

\section{References}

[1] Xia Yuanyou, Li Mei. Evaluation method research of slope stability and its developing trend [J]. Chinese Journal of Rock Mechanics and Engineering. 2002, 21 (7): 1087-1091.

[2] Fang Yushu. The lowest solution of slice method for slope stability analysis [J]. Chinese Journal of Geotechnical Engineering. 2008, 30 (3): 331-335. 
[3] Wu Liudong, Su Aijun, Huo Xin, Qi Zhenyu. Comparison and analysis of slope safety factor by different limit equilibrium methods [J]. Water Resources and Power. 2013, 31 (12): 151154.

[4] Chen Z Y, Morgenstern N R. Extensions to the generalized method of slices for stability analysis [J]. Canadian Geotechnical Journal. 1983, 20 (1): 104-119.

[5] Su Aijun, Zou Zongxing, Lu Zhichun, Wang Jinge. The inclination of the interslice resultant force in the limit equilibrium slope stability analysis [J]. Engineering Geology. 2018, 240: 140-148.

[6] Huang Runqiu, Xu Qiang. Application of explicit Lagrangian finite-difference method in rock slope engineering $[\mathrm{J}]$. Chinese Journal of Rock Mechanics and Engineering. 1995, 14 (4): 346-354.

[7] Carol Matthewsa, Zeena Farooka, Peter Helm. Slope stability analysis-limit equilibrium or the finite element method [J]. Ground Engineering. 2014, 48 (5): 22-28.

[8] Xiong Zheng, Li Xianfu, Yand Liwei. Analysis of slope stability at reservoir bank with FLAC $^{3 \mathrm{D}}[\mathrm{J}]$. Journal of Wuhan Institute of technology. 2007, 29 (2): 27-30.

[9] Han Wandong, Gu Mingyu, Yang Xiaoyun, Qiao Yanwei, Wang Xingguo. Slope stability based on FLAC3D numerical simulation [J]. Journal of Liaoning Technical University (Natural Science). 2013, 32 (9): 1204-1208.
[10] Zhou Jian, Deng Maolin, Li Zhuojun, Zhang Fuling, Lin Yan. Analysis on the Formation and Apparent-dip Lateral Sliding Mechanism of Shanshucao Landslide in the Three Gorges Reservoir Area [J]. Journal of Disaster Prevention and Mitigation Engineering. 2020, 40 (6): 860-866.

[11] Ministry of Land and Resources of the People's Republic of China. Monitoring code of rockfall, landside and debris flow: DZ/T 0221-2006 [S]. Beijing: Standards Press of China, 2006.

[12] Ministry of Housing and Urban-Rural Development of the People's Republic of China. Technical code for building slope engineering: GB 50330-2013 [S]. Beijing: China Architecture \& Building Press, 2013.

[13] Yu Zhongxiang, Ren Weizhong, Fu Guijun, Zhang Jipeng, Shen Kai. Failure Forms and Stability Analysis of Layered Rock Slope Based on FLAC ${ }^{3 \mathrm{D}}[\mathrm{J}]$. Journal of Shaoxing University. 2020,40 (10): 20-28.

[14] Lu Wenbin, Geng Haishen, Wei Sailajia. Stability of Zhangjiawan Landslide Based on Limit Equilibrium Method and Midas/GTS [J]. Science Technology and Engineering. 2021, 21 (11): 4369-4378.

[15] Aijun Su. Principle and method of landslide stability evaluation -- improvement of slices method [M]. Wuhan: China University of Geosciences Press, 2008. 